\title{
An Update on the Structure of the Parathyroid Gland
}

\author{
Huayue Chen ${ }^{*}$, Takao Senda $^{1}$, Shoichi Emura ${ }^{2}$ and Kin-ya Kubo ${ }^{3}$ \\ ${ }^{1}$ Department of Anatomy, Gifu University Graduate School of Medicine, 1-1 Yanagido, Gifu 501-1194, Japan \\ ${ }^{2}$ Nursing Course, Gifu University School of Medicine, 1-1 Yanagido, Gifu, 501-1194, Japan \\ ${ }^{3}$ Seijoh University Graduate School of Health Care Studies, 2-172, Fukinodai, Tokai, Aichi 476-8588, Japan
}

\begin{abstract}
The parathyroid glands hold a special place in human anatomy, since they were the last major organ to be recognized by humans. The glands are recognized in all vertebrate animals higher than fish, and are derived from the pharyngeal pouches. The molecular signaling pathways that are involved in determining the differentiation of the glands are being elucidated. Studies in mice have demonstrated that the transcription factor encoded by Glial cells missing 2 $(\mathrm{Gcm} 2)$ is a key regulator of parathyroid development. Recent studies indicate that the tetrapod parathyroid glands and the gills of fish are evolutionarily related structures, and that the parathyroid glands likely come into being as a result of the transformation of the gills during tetrapod evolution. The parathyroid chief cells play a central role in calcium homeostasis by sensing changes in extracellular calcium and releasing parathyroid hormone (PTH) to correct or maintain normal blood calcium levels. Chief cells undergo morphologic changes corresponding to different stages of the secretory cycle. Parathyroid oxyphil cells derived from chief cells as aging or some metabolic derangements, have the potential to produce PTH, PTH-related protein, and calcitriol. The existence of water-clear cells is confirmed in some kinds of animals, which may represent hyperfunction of the parathyroid gland. The presence of water-clear cell is associated with parathyroid hyperplasia or parathyroid adenoma. The molecular regulation of PTH synthesis and release indicates that parathyroid cells detect changes of the extracellular calcium levels by calcium-sensing receptor, which plays a central role in regulating PTH secretion.
\end{abstract}

Keywords: Parathyroid gland, morphology, embryology, evolution, chief cell, oxyphil cell, water-clear cell, parathyroid hormone.

\section{INTRODUCTION}

The parathyroid glands hold a special place in human anatomy and physiology, since they were the last major organ to be recognized in humans [1]. They were first identified by the English biologist Richard Owen in 1850 and were discovered in humans in 1880 by Ivar Sandström, a Swedish medical student [2]. Later, the relationship of the glands to severe bone disease was established. Since the middle of the 20th century, a number of histological and ultrastructural studies have been done on the parathyroid glands of numerous animal species [3-6]. The primary function of the parathyroid gland is to produce and release an 84- amino acid hormone called parathyroid hormone (PTH), which is involved in calcium homeostasis. Serum calcium plays many physiological functions including neuromuscular excitability, muscle contraction, blood coagulation and bone mineralization [7]. The importance of calcium in biological systems and the necessity for organisms to tightly regulate calcium homeostasis has been firmly established [8]. Calcium homeostasis is maintained by an efficient system that is composed of parathyroid glands, bone, kidney and intestine. In this system, parathyroid glands are the most

*Address correspondence to this author at the Department of Anatomy, Gifu University Graduate School of Medicine, 1-1 Yanagido, Gifu, 501-1194, Japan; Tel: +81 58230 6295; Fax: +81 58230 6298;

E-mail: huayue@gifu-u.ac.jp important endocrine regulator to maintain the calcium homeostasis in the circulation [7].

The production and secretion of PTH in the parathyroid glands are controlled by the membrane-bound calciumsensing receptor $(\mathrm{CaR})$, which regulates PTH secretion by sensing the changes of extracellular calcium concentration [9]. The discovery of the $\mathrm{CaR}$ and its role in calcium homeostasis has led to a better understanding of the regulation mechanism for PTH secretion and synthesis. Recent molecular studies have revealed important roles for a number of transcription factors, which include Glial cells missing $2(\mathrm{Gcm} 2)$, the earliest marker of the parathyroid gland [10]. The discovery of $\mathrm{Gcm} 2$ as an essential transcription factor for parathyroid development has led to a new theory on the developmental and evolutional origins of parathyroid glands [11]. The present review article provides an overview of studies on the morphology of the parathyroid glands, including anatomy, embryology, and histology. The parathyroid secretion regulation by $\mathrm{CaR}$ is also reviewed.

\section{GROSS ANATOMY OF THE PARATHYROID GLAND}

The parathyroid glands are small pale brown structures, measuring approximately $6 \mathrm{~mm}$ in craniocaudal dimension and 3 to $4 \mathrm{~mm}$ in transverse dimension, with a somewhat flattened oval disk appearance (Fig. 1). There is a considerable variation between the individuals with respect 
to parathyroid size. Usually there are four parathyroid glands and each one is about the size of a split pea, weighing 30 to $40 \mathrm{mg}$, but this can be range from 2 to 6 glands, with some authors reporting up to 12 glands [12,13]. Supernumerary parathyroid glands are found in healthy individuals, most commonly with a 5th gland located in the cervical thymus $[7,12,14]$. The combined weight of all parathyroid glands is $120 \mathrm{mg}$ in adult men and $142 \mathrm{mg}$ in adult women. Any individual gland of weight over $60 \mathrm{mg}$ is considered enlarged and abnormal [15]. The anatomic location of the superior parathyroid glands is relatively constant due to the close relationship between these glands and the thyroid gland. They usually lie at the middle of the posterior border of the thyroid lobe, above the level at which the inferior thyroid artery crosses the recurrent laryngeal nerve. The inferior parathyroid glands are usually situated below the inferior artery near the lower pole of the thyroid gland. The next most common site is within $1 \mathrm{~cm}$ of the lower pole of the thyroid gland. Aberrant inferior parathyroid glands may descend along the inferior thyroid veins in front of the trachea, and may even track into the superior mediastinum in company with thymic tissues, for which there is an embryological explanation. The incidence of intrathyroidal parathyroid tissue is uncommon, approximately $2 \%$ [15].

The arterial supply arises from the inferior thyroid artery or from the rich anastomotic network formed from vessels arising from both superior and inferior thyroid arteries [12, 15]. The venous drainage is usually into the thyroid plexuses. Lymph drainage is via paratracheal or deep cervical lymph nodes. The parathyroid glands are innervated by the sympathetic, parasympathetic, and sensory nerves [5,
$6,16,17]$. The cells of origin of autonomic nerve fibers innervating the parathyroid gland are found in the superior cervical ganglion and in the dorsal nucleus of the vagus nerve $[5,6]$. Several studies suggest that the vagus nerve has an inhibitory effect and the sympathetic nerve has a stimulatory effect upon the functional condition of the parathyroid gland $[5,6]$.

The parathyroid cyst is a rare lesion, but has clinical significance because it can mimic a thyroid mass and can be associated with hyperparathyroidism. Some ciliated cysts are observed in young hamsters [18]. The frequency of parathyroid cysts decreases with aging. The cyst possesses the features of the pharyngeal epithelia and may arise from embryological remnants of pharyngeal pouches undergoing cystic degeneration and entrapping portions of parathyroid tissue [18]. The parathyroid follicles sometimes occur in various species of animals. They may appear in patients with hyperparathyroidism. Some parathyroid follicles exist in senescence-accelerated mouse strain P6 (SAMP6) [19]. The follicles are surrounded with parathyroid chief cells. Numerous secretory granules are seen at the luminal surface. The serum PTH level is higher and parathyroid chief cells show hyperfunction morphologically. Accumulating evidence suggests that parathyroid follicles are developed to meet the need for storage of PTH that can later be released into the blood.

\section{DEVELOPMENT AND EVOLUTION OF THE PARATHYRIOD GLAND}

In mammalian development, the parathyroid glands, together with the thymus, thyroid, and ultimobranchial

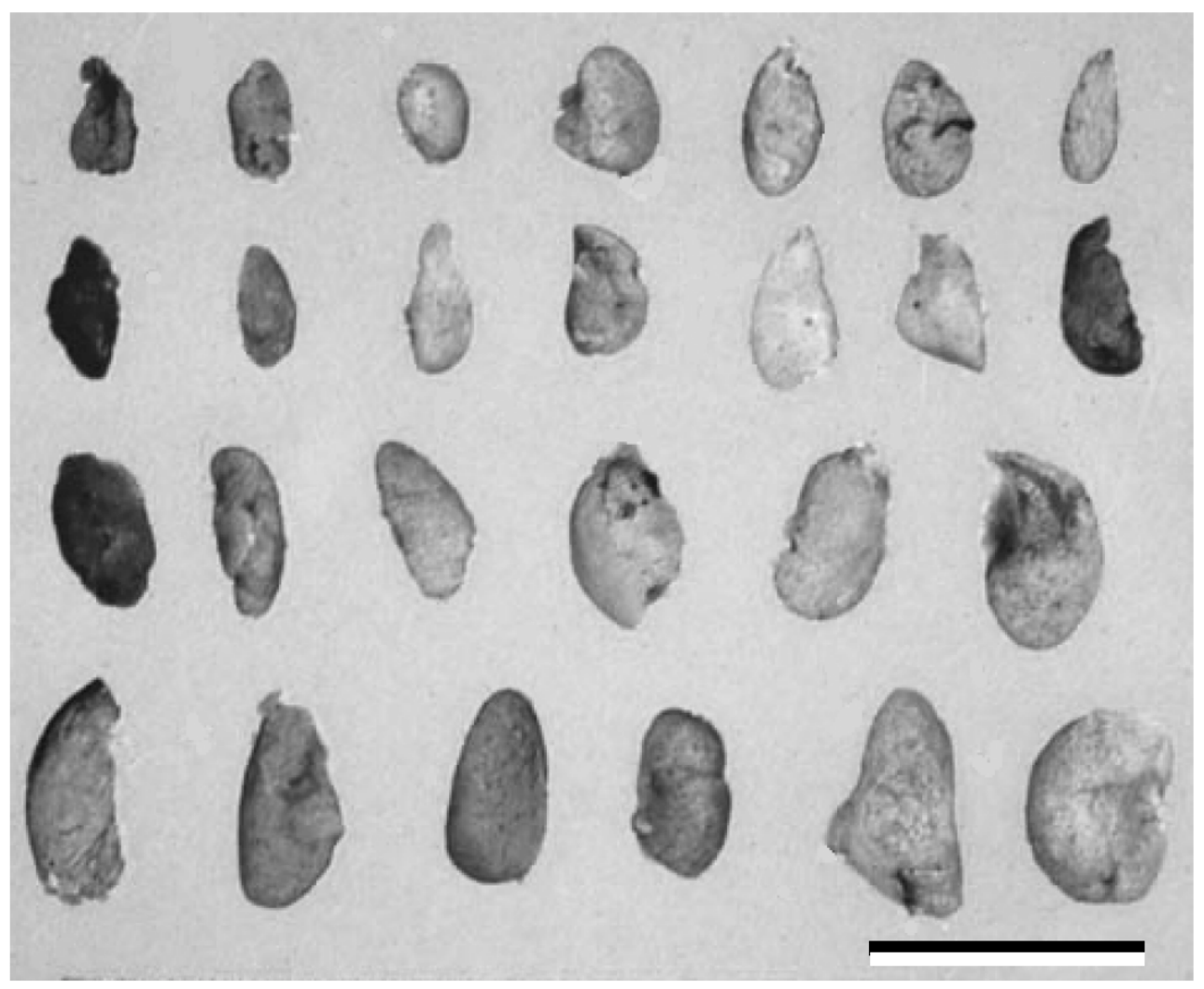

Fig. (1). Human parathyroid glands. There is a considerable variation between the individuals with respect to parathyroid size. Scale bar=10 $\mathrm{mm}$. 


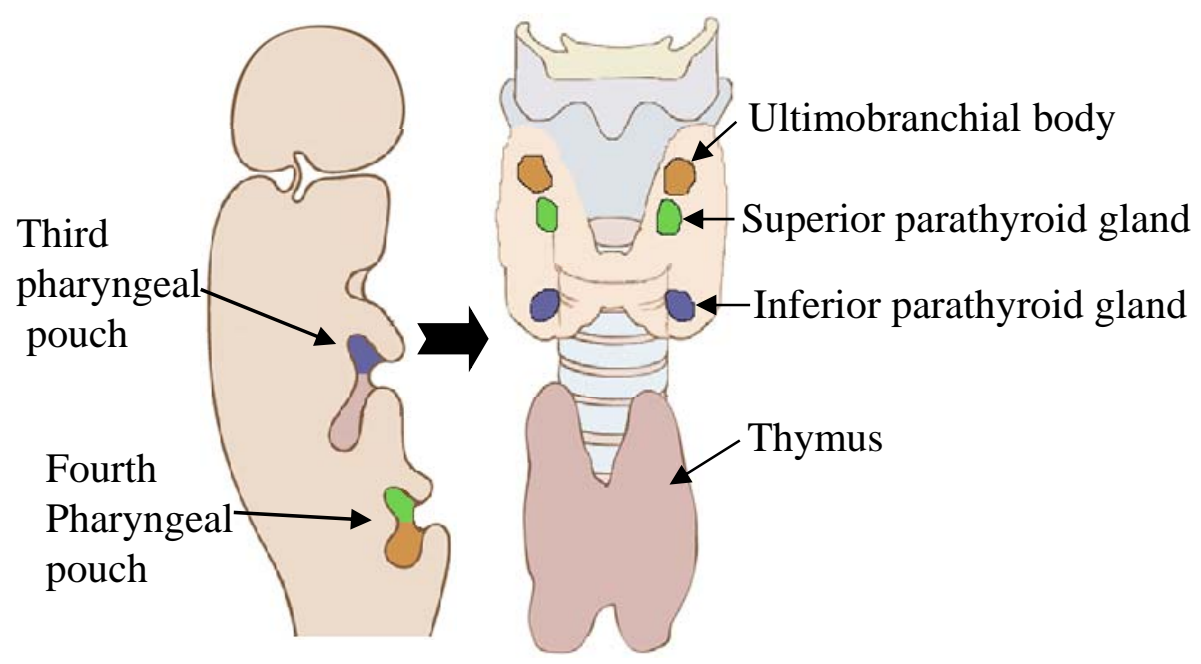

Fig. (2). Diagram of normal pharyngeal organ development. The superior parathyroid glands and ultimobranchil body derives from the 4th pharyngeal pouch. The inferior parathyroid glands originate from the $3 \mathrm{rd}$ pharyngeal pouch along with the thymus.

bodies, are derived from the third and fourth pharyngeal pouches (Fig. 2), and cranial neural crest cells that arise from the embryonic hindbrain [13,15]. In humans, the superior parathyroid glands are derived from the endoderm of the fourth pharyngeal pouches. The inferior parathyroid glands develop from two common parathyroid/thymus primordia, which are derived from endodermal cells of the third pharyngeal pouches. Later in development, the inferior glands separate from the thymus and come to lie caudal to the thyroid and superior parathyroid glands. The relationship of the inferior parathyroid glands and the thymus explains the variable position of the inferior parathyroid glands, as the thymus has a long course of descent into the superior mediastinum and frequently presents in ectopic locations. This embryologic development also explains the many possible locations of ectopic parathyroid tissue or supernumerary glands $[13,15]$.

In mice, there is only one pair of parathyroid glands, which originate from the endoderm derived epithelial layer that lines the third pharyngeal pouches; this is homologous to the inferior parathyroid glands in humans. The mouse parathyroid glands develop with the thymus from the 3rd pharyngeal pouch endoderm beginning at embryonic day (E) E8.0. The 3rd pharyngeal pouches become visible by E9.510 , and differentiate from E10.5 [13, 15, 20]. An epithelial outgrowth of the pharyngeal pouch endoderm begins to form the bilateral parathyroid/thymus common primordia, which are divided into specific dorsal and anterior presumptive parathyroid domains and ventral and distal presumptive thymus domains. The parathyroid and thymus can be recognized at E12.5-13 [21], and separation of the parathyroid glands from the thymus occurs by E14-14.5, when both structures migrate towards the caudal end [22]. The parathyroid glands become situated posterior to the lobes of the thyroid, whereas the thymus descends further in the direction of the heart. Thus, the organogenesis of the parathyroid and thymus are closely linked at the early stage of development. At this stage, the parathyroid glands show a high degree of vascularity, and their innervation is derived from the cervical sympathetic ganglia and branches of the vagus nerve. Expression of PTH gene occurs as early as at
E11.5, before separation from the thymus, and is maintained throughout development [23].

In addition to the endodermal cells of the pharyngeal pouches, cells originating from the neural crest of rhombomeres 6 and 7 of the hindbrain also contribute to the anlage of the parathyroid glands [24]. The molecular signaling pathways that are involved in determining the differentiation of the pharyngeal pouch endoderm into parathyroid cells are being elucidated by studies of patients with hypoparathyroidism and appropriate mouse models. Studies in mice have demonstrated that the transcription factor encoded by $\mathrm{Gcm} 2$ is a key regulator of parathyroid gland development. The null mutation of $\mathrm{Gcm} 2$ in mice leads to agenesis of the parathyroid glands from E12 onwards $[10,23]$. At E11.5, the glands do not initiate PTH expression. Loss of PTH secreting cells is caused by increased cell death [10]. In the chick $\mathrm{Gcm} 2$ is expressed in the third and fourth pouch, reflecting the development of parathyroid glands from both of the 3rd and 4th pharyngeal pouches [13]. In humans, homozygous inactivating mutations in $\mathrm{Gcm} 2$ have been related to the familial autosomal recessive and dominant isolated forms of hypoparathyroidism. Gcm2 mutated individuals typically exhibit undetectable or residual PTH levels. Evidence suggests that some parathyroid adenomas might be associated with a dysregulation of $\mathrm{Gcm} 2$ expression. Both reduced and enhanced $\mathrm{Gcm} 2$ expression levels are found in some human parathyroid adenoma [25]. The expression of $\mathrm{Gcm} 2$ is restricted to the parathyroid glands, and if this gene is mutated, the parathyroid glands fail to form. Therefore, $\mathrm{Gcm} 2$ is the key regulating transcription factor for parathyroid gland development. The continued expression of high levels of $\mathrm{Gcm} 2$ in mature parathyroid glands suggests that it is required for maintenance of parathyroid cell differentiation.

The discovery of $\mathrm{Gcm} 2$ as an essential transcription factor for parathyroid gland development disclosed another, unexpected source of circulating PTH, the thymus [10]. A recent phylogenetic analysis of $\mathrm{Gcm} 2$ has led to a new theory that parathyroid glands in tetrapods are transformed from the gills of fish during evolution [11, 26, 27]. It has 
long been held that the parathyroid glands and PTH evolved with the emergence of the tetrapods, reflecting a need for new controls on calcium homeostasis in terrestrial, rather than aquatic, environments. This event freed the tetrapods from relying on calcium uptake from the water by giving them the ability to internally regulate their serum calcium levels. Amphibians have parathyroid glands, whereas fish do not have these glands. Recent studies have indicated that the gill buds are homologous structures that play a similar role in controlling calcium levels [11, 26, 27]. Gcm2 is expressed in the pharyngeal arch epithelium starting in the 2nd pouch before extending to the other pouches, and later in the internal gill buds in both zebrafish and dogfish [11]. Loss of $\mathrm{Gcm} 2$ results in loss of the gill buds [11,26], and also lead to cartilage defects [27]. It is therefore proposed that the internalization of $\mathrm{Gcm} 2$ positive region during the move to land lead to the formation of the tetrapod parathyroid gland. The tissue origin of $\mathrm{Gcm} 2$ expression domain, however, is in debate, as both an endodermal and ectodermal expression has been reported $[11,26]$. In amniotes $\mathrm{Gcm} 2$ domain is clearly endodermal, thus the issue of which tissue expresses $\mathrm{Gcm} 2$ is of particular importance if homology is to be assigned. $\mathrm{Gcm} 2$ is expressed in pharyngeal pouches of the teleost fish zebrafish and the small-spotted catshark Scyliorhinus canicula [11, 26, 27]. Its expression patterns indicate that the tetrapod parathyroid glands and the gills of fish are evolutionarily related structures, and that the parathyroid glands likely come into being as a result of the transformation of the gills during tetrapod evolution.

\section{MICROSCOPIC ANATOMY OF THE PARATHYROID GLAND}

Histologically, the parathyroid glands are bounded by a thin fibrous capsule that overlies a network of adipose tissue, blood vessels and glandular parenchyma (Fig. 3). The amount of stromal fibroadipose tissue increases with aging, eventually comprising approximately 50\% of the gland volume in elderly [28]. The parathyroid glands from a wide range of species exhibit similar morphologic features. A large number of ultrastructural studies of the normal parathyroid glands have been reported in mammals [4-6, 19].

\section{Parathyroid Chief Cell}

The parathyroid chief cells are the major cell type of the parathyroid glands in healthy subjects. Chief cells play a central role in calcium homeostasis by sensing changes in extracellular calcium and releasing the appropriate amount of PTH to correct or maintain normal blood calcium levels. Chief cells undergo morphologic changes corresponding to different stages of the secretory cycle [4-6, 19]. Chief cells in an inactive stage of their secretory cycle are cuboidal and have uncomplicated interdigitations between adjacent cells. There are numerous experiments, such as sympathectomy, electrical stimulation of vagus nerve, ovariectomy, hypophysectomy, and injection of calcium, propranolol, melatonin, and streptozotocin, suppress chief cells to release PTH (inactive stage). Experiments such as low calcium diet, vagotomy, hypergravity environment, pinectomy, and injection of estrogen, isoproterenol, and calcitonin, stimulate chief cells to enter active stage [6]. The cytoplasm contains poorly developed organelles and infrequent secretory granules (Fig. 4A). There are numerous lipid droplets, lysosomes or glycogen particles. Chief cells in the active stage are oval or polygonal in shape. The plasma membranes of adjacent chief cells purse a tortuous course with complex interdigitations. The nuclei are oval or spherical with occasional invaginations. The cells have rich free ribosomes and the rough endoplasmic reticulum. The Golgi complexes contain numerous prosecretory granules. The secretory granules of 150 to $200 \mathrm{~nm}$ in diameter are distributed around the Golgi complexes and peripheral cytoplasm. Some of them are situated close to the plasma membrane (Fig. 4B). In the electron microscopic autoradiograph of the newt parathyroid gland after injection of ${ }^{3} \mathrm{H}$-leucine, most silver grains are seen over the rough endoplasmic reticulum at 15 minutes, over the Golgi complexes at 30 minutes, and over secretory granules at 60 minutes [5]. Similar results have been reported in the rat parathyroid gland [6]. From these findings, the synthesis of secretory protein is related to ribosomes lining the rough endoplasmic reticulum, newly synthesized secretory protein is transferred from the endoplasmic reticulum to the Golgi complexes and secretory granule. Immunocytochemical localization of PTH can be examined by using the protein A-gold technique. Protein Agold particles are concentrated over the secretory granules and Golgi vacuoles [5, 6, 29]. No particles are detected over the rough endoplasmic reticulum.

\section{Parathyroid Oxyphil Cell}

Another cell type in the parathyroid glands of certain animal species and humans is the oxyphil cell [4-6]. These cells are absent from the parathyroid glands of the rat,

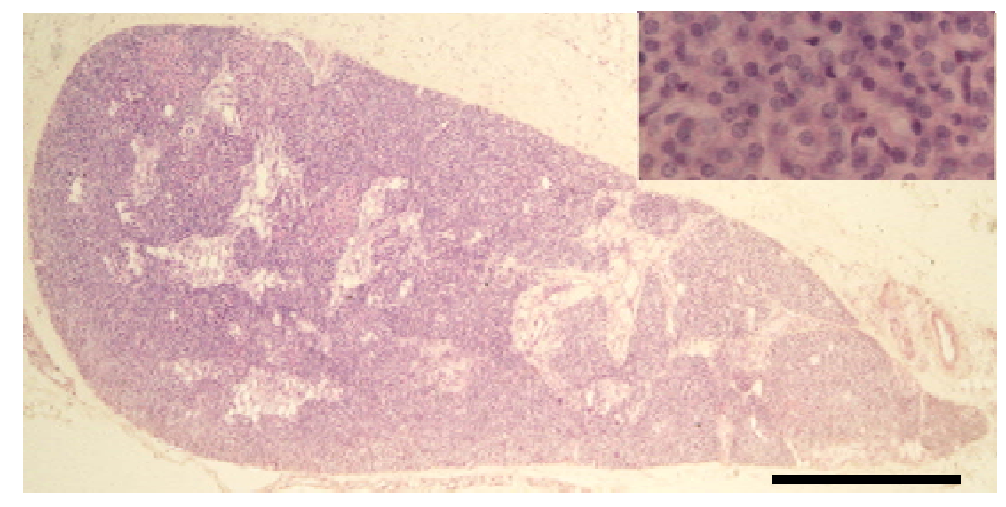

Fig. (3). Light micrograph of the human parathyroid gland. The gland comprises dense cords of chief cells clustered around capillaries. Scale bar $=0.5 \mathrm{~mm}$. 

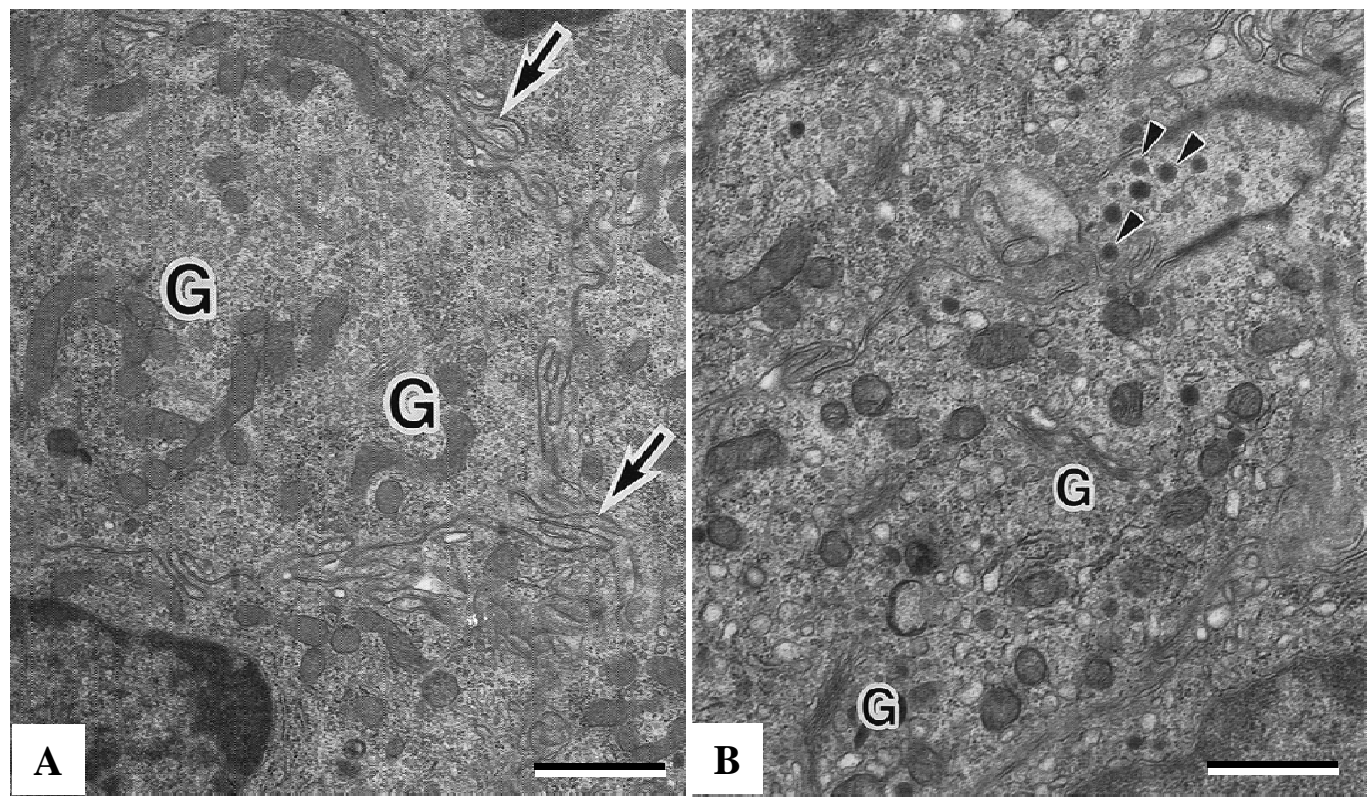

Fig. (4). Rat parathyroid chief cells of the inactive stage (A) and active stage (B). Inactive chief cells contain poorly developed Golgi complexes $(\mathrm{G})$ and infrequent secretory granules. Well developed Golgi complexes $(\mathrm{G})$ and numerous secretory granules (arrowheads) are found in the active chief cells. Scale bars $=2 \mu \mathrm{m}$

chicken, and many species of lower animals. Oxyphil cells are observed either singly or in small groups interspersed between chief cells. They are larger than chief cells and the abundant cytoplasm is filled with numerous large mitochondria (Fig. 5), suggesting a need for energy production. Mitochondria are also the site for vitamin D metabolism. Vitamin D $1 \propto \mathrm{OH}$ ase is very highly expressed in oxyphil cells [30]. The rough endoplasmic reticulum is scarce and the Golgi complex associated with few prosecretory granules is poorly developed. A few secretory granules, lysosomes, lipid droplets and glycogen particles are present. Oxyphil cells have been shown histochemically to have a higher oxidative and hydrolytic enzyme activity than chief cells associated with the marked increase in mitochondria. Transitional oxyphil cells between the chief cells and oxyphil cells are observed in the parathyroid gland $[5,6,31]$. Both transitional and oxyphil cells are not altered in response to either short-term hypocalcemia or hypercalcemia in animals, but they may be increased in response to long-term stimulation of human parathyroid glands. It has been shown that the number of oxyphil cells increases with aging and some metabolic deragements. The cell increases dramatically in number especially in patients with chronic kidney disease [32].

Immunostaining has demonstrated oxyphil cells contain high levels of immunoreactive PTH, PTH-related protein (PTHrP), and calcitriol, indicating that these cells continue to produce PTH, PTHrP, and calcitriol. Gcm2, CaR, and vitamin D receptor are highly expressed by oxyphil cells [30], suggesting continued regulation of PTH by calcium, calcimimetrics, and vitamin D compounds. The parathyroid oxyphil cells express parathyroid-relevant genes found in the chief cells, suggesting the oxyphil cells are not simply degenerate chief cells. Oxyphil cells are derived from chief cells and release PTH in a regulated fashion, and also have the potential to produce autocrine/paracrine factors, such as PTHrP and calcitriol. Treatment of hyperparathyroidism in patients with chronic kidney disease increases the content of oxyphil cells in the glands [32]. The number of Oxyphil cells is highest in patients receiving the calcimimetic cinacalcet, suggesting a role for $\mathrm{CaR}$ activation in the genesis of these cells $[30]$.

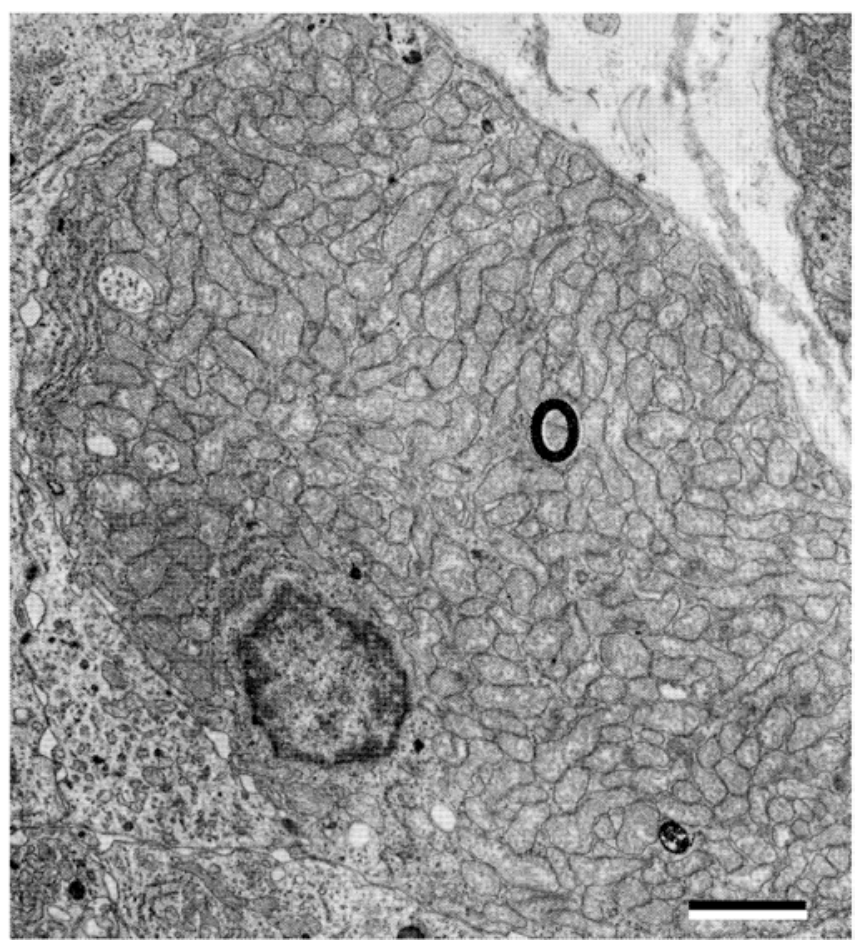

Fig. (5). Human parathyroid oxyphil cell filled with numerous mitochondria. Scale bars $=2 \mu \mathrm{m}$. 


\section{Parathyroid Water-Clear Cell}

The third cell type in the parathyroid glands is waterclear cell, which is extremely rare or absent in normal humans. The presence of water-clear cell is associated with parathyroid hyperplasia or parathyroid adenoma [33]. Even though water-clear cell hyperplasia or adenoma is very rare, it should be considered clinically in the differential diagnosis of water-clear cell lesions of the neck. Water-clear cells have been found in parathyroid glands from normal hamster, rabbit, possum, and echidna [34-36]. The water-clear cell possesses an oval or round nucleus with occasional indentations. The cytoplasm is filled, for the most part, with membrane-limited vacuoles (Fig. 6). Most vacuoles appear empty or contain finely particulate substance and thread-like materials. Ribosomes attach to the surface of some vacuoles, which resemble dilated cisternae of the rough endoplasmic reticulum in the chief cells. The water-clear cell is attached by desmosomes to the chief cells. There are free ribosomes, mitochondria, and glycogen particles. Golgi complexes are relatively well-developed and contain many coated vesicles and prosecretory granules. Secretory granules are occasionally observed in the peripheral cytoplasm. Transitional forms between the chief cells and water-clear cells are observed in the parathyroid gland [33, 35]. Waterclear cells are also present in SAMP6 mouse, the murine model for senile osteoporosis [37]. The number of waterclear cells increases with aging, which are fairly consistent with the change of serum PTH level. The existence of waterclear cell may represent hyperfunction of the parathyroid gland in SAMP6 mice [37].

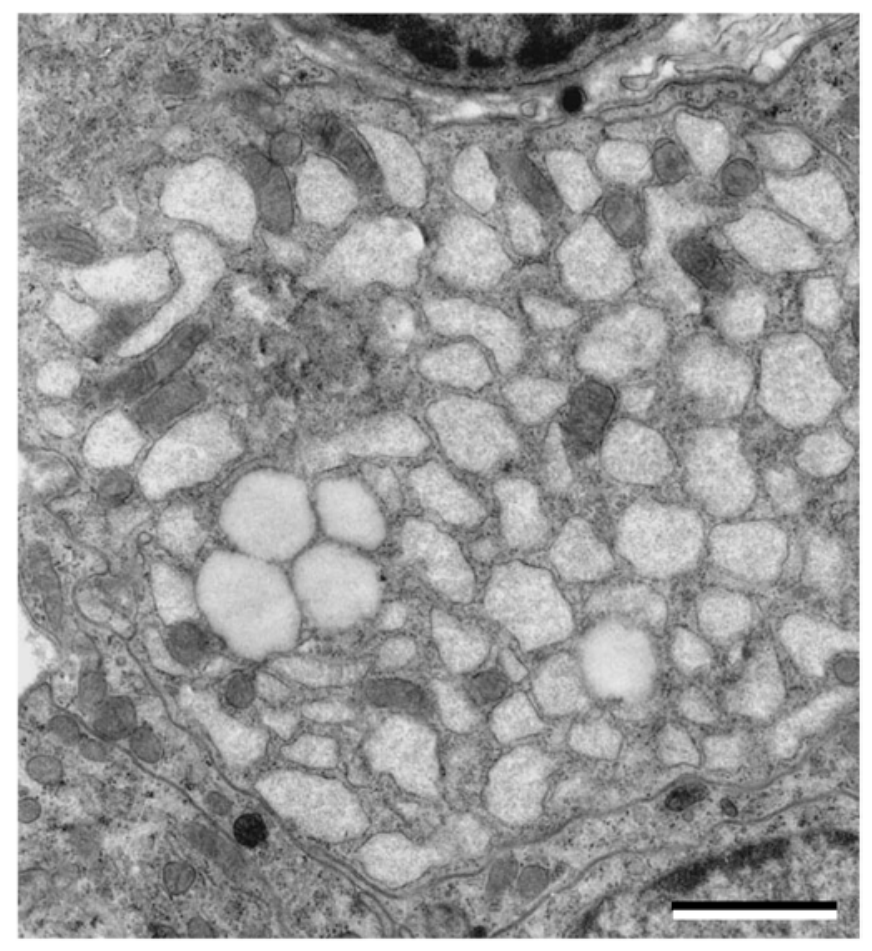

Fig. (6). Hamster parathyroid water-clear cell filled with numerous vacuoles. Scale bars $=2 \mu \mathrm{m}$.

\section{Other Cells}

The mast cell is described in the histology of normal human parathyroid glands. Mast cell is an important immune cell connecting innate and adaptive immune responses, as well as connecting immune system with the nervous system [38]. The mast cell was first noted in parathyroid glands by Erdheim in 1903 and then described in the histology of normal human parathyroid glands [39]. The parathyroid mast cells are found in the connective tissues adjacent to blood capillaries. The granules within the mast cells exhibit uniform or heterogeneous electron density (Fig. 7A). Mast cells are likely to be involved in PTH secretion, playing a role in the pathogenesis of osteoporosis [39, 40]. The parathyroid glands also have lipid-storing cells, which are located in the interstitial tissues and invariably contain several lipid droplets within the cytoplasm (Fig. 7B). The lipid droplets of the cell might be a storage site or a detoxication site for lipophilic agents, such as vitamin A. This cell could perform some special functions to affect parathyroid chief cells [41]. There is an ED2immunoreactive macrophage in the parathyroid glands. Macrophages, containing many lysosomes of heterogeneous contents, are observed in the perivascular regions (Fig. 7C). Some cells locate among the chief cells. The number of parathyroid macrophages increased with aging. Some macrophages showed intimate physical contacts with chief cells, suggesting macrophages could signal towards the chief cell, affecting the parathyroid function [42].

The parathyroid functional cytology indicates that chief cells undergo periodic changes between active and inactive stages corresponding to extracellular environments. Oxyphil cells derived from chief cells are observed in elderly or some metabolic deragements. The existence of water-clear cells is associated with hyperfunction of the parathyroid gland. Parathyroid mast cells, macrophages, and lipid-storing cells signal towards chief cells to affect parathyroid function (Fig. 8).

\section{THE REGULATION OF PTH SYNTHESIS AND SECRETION}

The parathyroid glands play a pivotal role in regulating extracellular calcium homeostasis, which is important to many physiological processes such as muscle contraction, blood coagulation, and synaptic activity. The glands detect changes in the levels of calcium in blood by $\mathrm{CaR}$, which in turn modulates the secretion of PTH [43]. The parathyroid chief cells in human and many animal species store relatively small amounts of preformed hormone but respond quickly to variations in need for hormone by changing the synthesis rate. PTH is first synthesized on ribosomes of the chief cells as a Prepro PTH of 115 amino acids, containing the signal fragment of 25 amino acids. Prepro PTH is rapidly converted within 1 minute or less of its synthesis to pro PTH by the cleavage of the $\mathrm{N}$-terminal sequence of 25 amino acids (Fig. 9). The resultant pro PTH is subjected to further proteolysis as it passes through the endoplasmic reticulum to the Golgi complex. Enzymes with trypsin-like and carboxypeptidase-like activity within membranes of the Golgi complex cleave a hexapeptide from the $\mathrm{N}$-terminal end of the molecule [44]. Biologically active PTH of 84 amino acids is packaged into macromolecular aggregates in the Golgi complex for subsequent storage (Fig. 9). A part of biosynthetic precursors and active PTH is degraded by lysosomal enzymes intracellularly. Under certain conditions of increased demand, such as low extracellular calcium 

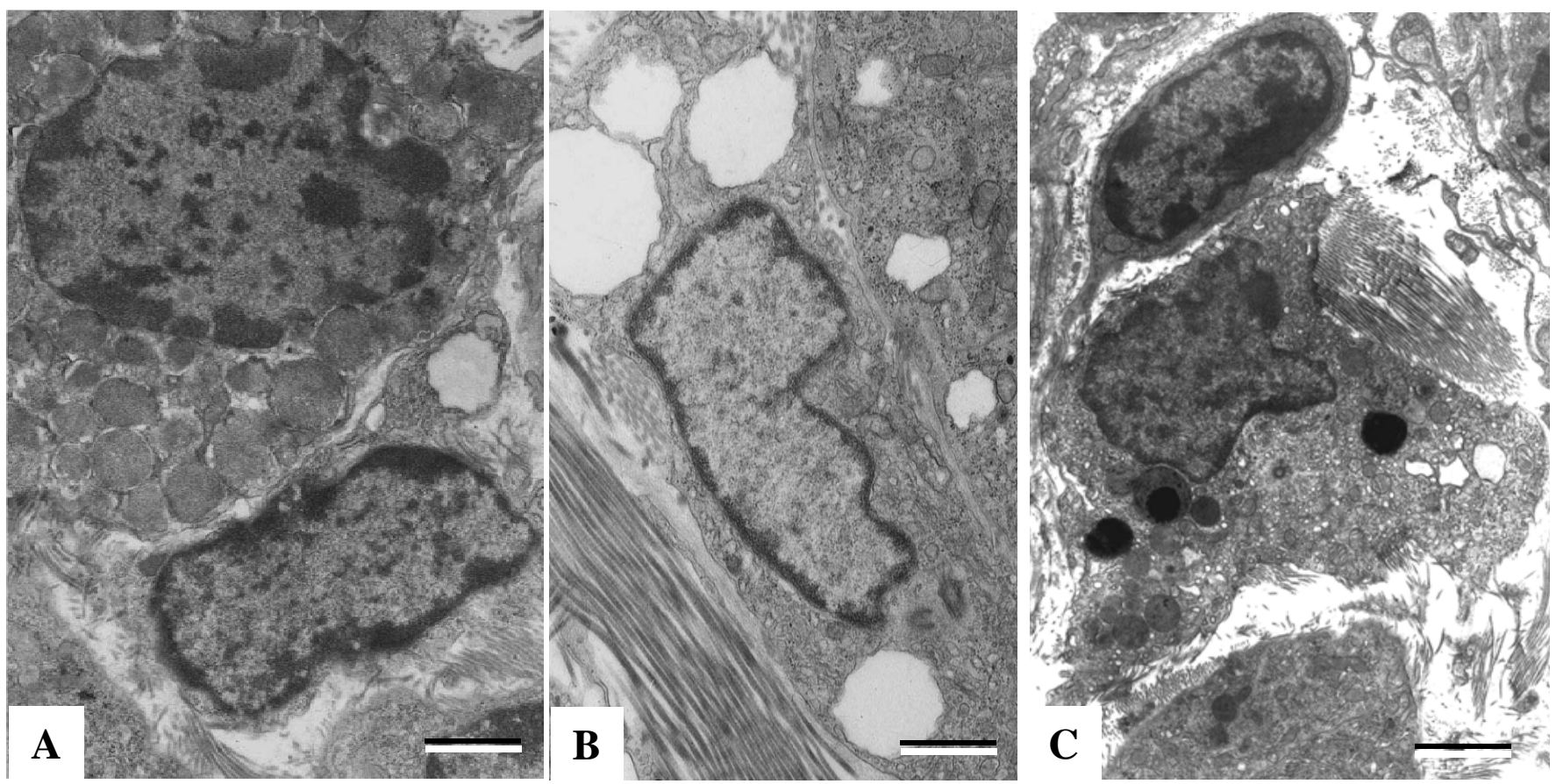

Fig. (7). The parathyroid mast cell (A), lipid storing cell (B), and macrophage (C). Scale bars=2 $\mu \mathrm{m}$.

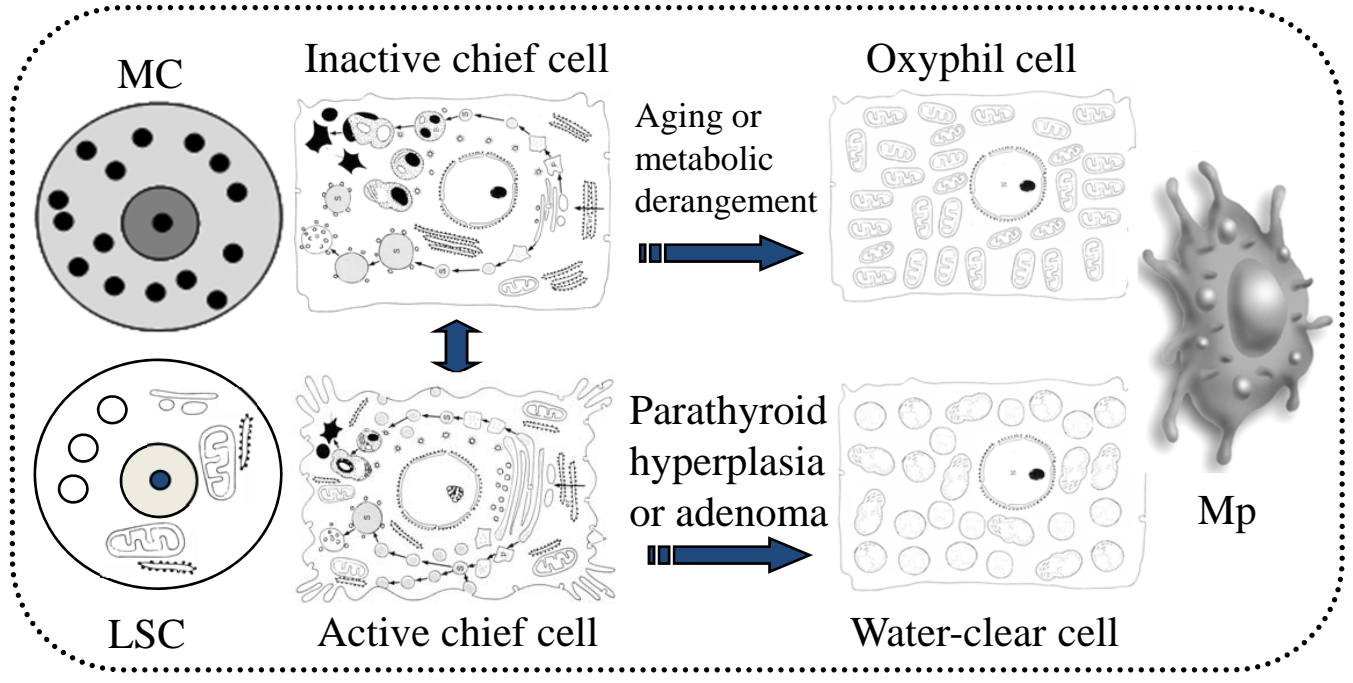

Fig. (8). Diagram of the parathyroid functional cytology. Chief cells undergo periodic changes between active and inactive stages corresponding to extracellular environments. Oxyphil cells derived from chief cells are seen in elderly or some metabolic derangements. The presence of water-clear cells is associated with parathyroid hyperplasia or adenoma. Mast cells (MC), macrophages (Mp), and lipid storing cells (LSC) signal towards chief cells to affect parathyroid function.

concentration, PTH is released into the extracellular space $[6,44]$. Serum calcium, phosphorus, and vitamin D metabolites play a role in regulating PTH synthesis and secretion $[44,45]$. While vitamin D metabolites act via the vitamin D receptor present in the parathyroid cells, calcium and phosphate influence the presence of proteins that either inhibit or enhance Prepro PTH mRNA degradation. Calcium concentration influences the fate of synthesized PTH. Most of the newly synthesized PTH remains intact in the presence of hypocalcemia, but it is degraded to a large extent in the presence of hypercalcemia [45].

Various experimental models have been used to study the regulation of PTH secretion. The parathyroid cells are exposed to high levels of extracellular calcium, a relative increase in the levels of cytosolic calcium is detected, which correlates with the suppression of PTH secretion. High extracellular calcium increase the production of both inositol 1,4,5 triphosphate and diacylglycerol, which are recognized as components associated with receptor-mediated intracellular calcium mobilization [46]. These evidences suggest that there is a receptor at the parathyroid cell surface sensitive to extracellular calcium that regulated PTH secretion through the mobilization of intracellular calcium [47]. In 1993, the first CaR was cloned from a bovine parathyroid gland by Brown et al. [50]. Structurally, CaR conforms to that of typical $\mathrm{G}$ protein-coupled receptor with a 


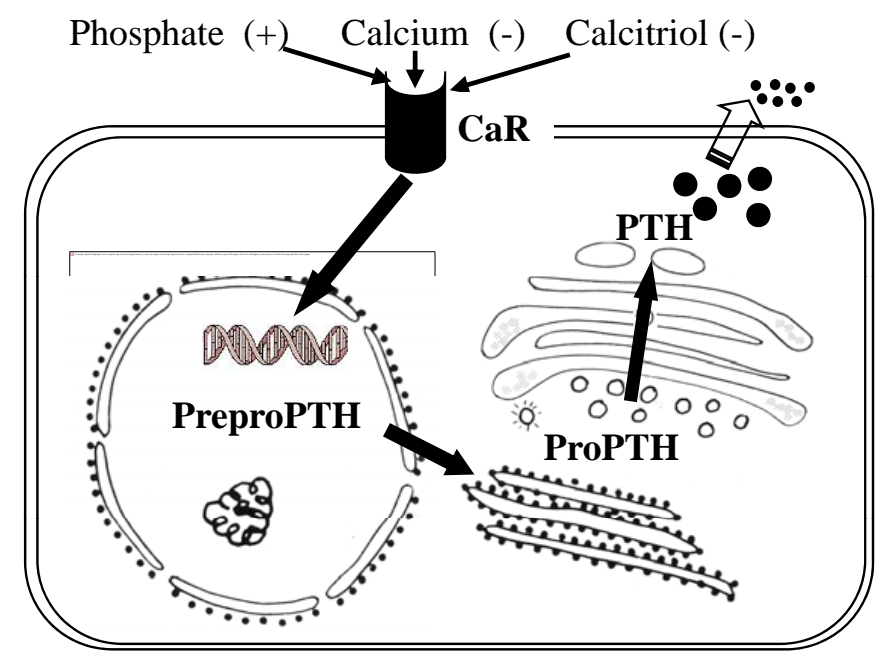

Fig. (9). Diagram of PTH synthesis and secretion in the parathyroid chief cell. The deactivation of calcium-sensing receptor (CaR) stimulates synthesis of prepro PTH, which is rapidly converted to pro PTH. Pro PTH is transported from endoplasmic reticulum to Golgi complex, where it is converted to active PTH and packaged into secretory granules. Under certain conditions, PTH is released to extracellular space.

particularly large extracellular domain of 612 amino acids, a classic hydrophobic, 7-membrance-spanning domain of 250 amino acids, and an unusually long carboxyl terminal intercellular tail of 216 amino acids [48]. Studies examining both the biochemical and functional properties of CaR have provided insight into how the receptor's 3 distinct structural regions influence its expression and function [49]. The receptor is processed as a dimmer in the endoplasmic reticulum where it is glycosylated with high mannose carbohydrates from where it moves to the Golgi complex to be further modified with complex carbohydrates and finally localizes to the plasma membrane $[49,50]$. A large fraction of $\mathrm{CaR}$ expressed in parathyroid cells is localized to caveolae, which are regions of the cell membrane containing signaling molecules and scaffolding proteins [51].

Activation of $\mathrm{CaR}$ by raising extracellular calcium concentrations is shown to initiate transduction through pathways to be linked directly to decrease in PTH release from parathyroid chief cells. Conversely, the effect of deactivation of $\mathrm{CaR}$ by a small decrease in extracellular calcium levels is to stimulate PTH secretion. There are recent data showing that CaR signaling decreases the level of PTH mRNA produced in parathyroid cells, suggesting an additional means by which the receptor limits the level of circulating PTH [52]. CaR-regulated reduction of PTH mRNA levels has been shown to require gene transcription and an increase in cytosolic calcium levels [53]. $\mathrm{CaR}$ is negatively regulate the proliferation of parathyroid cells based on the evidence of greater parathyroid hyperplasia associated with decreased $\mathrm{CaR}$ function, as seen in patients with neonatal severe hyperparathyroidism, or reduced expression in parathyroid adenomas [54]. Marked parathyroid cellular hyperplasia has also been observed in $\mathrm{CaR}$ knockout mice [55]. $\mathrm{CaR}$ is now known to play a central role in calcium homeostasis primarily through regulation of PTH secretion $[43,50]$.

\section{CONCLUSION}

The parathyroid glands are small organs about the size of a split pea, located closely associated with the thyroid gland. The glands, together with the thymus, thyroid, and ultimobranchial bodies, are derived from the third and fourth pharyngeal pouches. Recent molecular studies demonstrate that the transcription factor $\mathrm{Gcm} 2$ is a key regulator of parathyroid development. Phylogenetic researches indicate that the gills of fish are evolutionarily related structures of parathyroid glands, and that the parathyroid glands likely come into being as a result of the transformation of the gills during tetrapod evolution. Histological and ultrastructural studies have been extensively done on the parathyroid glands of numerous animal species. Chief cells are the major cell type of the parathyroid glands in healthy subjects. Chief cells synthesize and secrete PTH to correct or maintain normal blood calcium levels, by sensing changes in extracellular calcium. Chief cells undergo ultrastructural changes corresponding to different stages of the secretory cycle. Oxyphil cells derived from chief cells as aging or some metabolic derangement, have the potential to produce PTH, PTHrP, and calcitriol. The existence of water-clear cells is confirmed in some kinds of animals, which may represent hyperfunction of the parathyroid gland. The presence of waterclear cell is associated with parathyroid hyperplasia or parathyroid adenoma. The molecular regulation of PTH synthesis and secretion indicates that the parathyroid chief cells detect changes in the levels of calcium in blood by $\mathrm{CaR}$, which in turn modulates the secretion of PTH. CaR is now known to play a central role in regulating PTH secretion.

\section{CONFLICT OF INTEREST}

The authors confirm that this article content has no conflicts of interest.

\section{ACKNOWLEDGEMENTS}

Declared none.

\section{REFERENCES}

[1] Modarai B, Sawyer A, Ellis H. The glands of Owen. J R Soc Med 2004; 97: 494-5.

[2] Carney JA. The glandulae parathyroideae of Ivar Sandström. Contribution from two continents. Am J Surg Pathol 1996; 20: 1123-44.

[3] Lever DJ. Fine structural appearances in the rat parathyroid. J Anat 1957; 91: 73-81.

[4] Altenähr E. Ultrastructural pathology of parathyroid glands. Curr Top Pathol 1972; 56: 1-54. 
[5] Isono H, Shoumura S, Emura S. Ultrastructure of the parathyroid gland. Histol Histopathol 1990; 5: 95-112.

[6] Shoumura S, Emura S, Isono H. The parathyroid gland under normal and experimental conditions. Kaibogaku Zasshi 1993; 68: 5-29.

[7] Ramasamy I. Recent advances in physiological calcium homeostasis. Clin Chem Lab Med 2006; 44: 237-73.

[8] Carafoli E. The calcium-signalling saga: tap water and protein crystals. Nat Rev Mol Cell Biol 2003; 4: 326-32.

[9] Chang W, Shoback D. Extracellular $\mathrm{Ca}^{2+}$-sensing receptors: an overview. Cell Calcium 2004; 35, 183-96.

[10] Günther T, Chen ZF, Kim J, et al. Genetic ablation of parathyroid glands reveals another source of parathyroid hormone. Nature 2000; 406: 199-203.

[11] Okabe M, Graham A. The origin of the parathyroid gland. Proc Natl Acad Sci USA 2004; 101: 1716-9.

[12] Seethala RR, Virji MA, Ogilvie JB. Pathology of the parathyroid glands. In: Barnes L, ed. Surgical pathology of the head and neck, vol. III. New York, NY: Informa Health Care 2009; pp. 1429-72.

[13] Carlson D. Parathyroid pathology: hyperparathyroidism and parathyroid tumors. Arch Pathol Lab Med 2010; 134: 1639-44.

[14] Gomes EM, Nunes RC, Lacativa PG, et al. Ectopic and extranumerary parathyroid glands location in patients with hyperparathyroidism secondary to end stage renal disease. Acta Cir Bras 2007; 22: 105-9.

[15] Sheffield EA. An approach to common pathological conditions in the parathyroid glands. CPD Cell Pathol 2002; 4: 135-8.

[16] Raybuck HE. The innervation of the parathyroid glands. Anat Rec 1952; 112: 117-23.

[17] Chen H, Shoumura S, Emura S. Nerve fibers in the parathyroid gland of the golden hamster (Mesocricetus auratus): immunohistochemical and ultrastructural investigations. Anat Histol Embryol 2005; 34: 34-7.

[18] Chen H, Hayakawa D, Emura S, et al. Occurrence of the parathyroid cyst in golden hamsters. Ann Anat 2000; 182: 493-8.

[19] Chen H, Emura S, Yao XF, Shoumura S. Morphological study of the parathyroid gland and thyroid $\mathrm{C}$ cell in senescence-accelerated mouse (SAMP6), a murine model for senile osteoporosis. Tissue Cell 2004; 36: 409-15.

[20] Moore-Scott BA, Manley NR. Differential expression of Sonic hedgehog along the anterior-posterior axis regulates patterning of pharyngeal pouch endoderm and pharyngeal endoderm-derived organs. Dev Biol 2005; 278: 323-35.

[21] Manley NR, Capecchi MR. Hox group 3 paralogs regulate the development and migration of the thymus, thyroid, and parathyroid glands. Dev Biol 1998; 195: 1-15.

[22] Blackburn CC, Manley NR. Developing a new paradigm for thymus organogenesis. Nat Rev Immunol 2004; 4: 278-89.

[23] Liu Z, Yu S, Manley NR. Gcm2 is required for the differentiation and survival of parathyroid precursor cells in the parathyroid/thymus primordia. Dev Biol 2007; 305: 333-46.

[24] Graham A, Okabe M, Quinlan R. The role of the endodermin the development and evolution of the pharyngeal arches. J Anat 2005; 207: 479-87.

[25] Correa P, Akerstrom G, Westin G. Underexpression of Gcm2, a master regulatory gene of parathyroid gland development, in adenomas of primary hyperparathyroidism. Clin Endocrinol (Oxf) 2002; 57: 501-5.

[26] Hogan BM, Hunter MP, Oates AC, et al. Zebrafish $\mathrm{gcm} 2$ is required for gill filament budding from pharyngeal ectoderm. Dev Biol 2004; 276: 508-22.

[27] Hanaoka R, Ohmori Y, Uyemura K, et al. Zebrafish gcmb is required for pharyngeal cartilage formation. Mech Dev 2004; 121: 1235-47.

[28] Johnson SJ. Changing clinicopathological practice in parathyroid disease. Histopathol 2010; 56: 835-51.

[29] Chen H, Hayakawa D, Emura S, et al. Effect of low calcium diet on the ultrastructure of the rat parathyroid gland. Okajimas Folia Anat Jpn 2001; 78: 153-60.

[30] Ritter CS, Haughey BH, Miller B, Brown AJ. Differential gene expression by oxyphil and chief cells of human parathyroid glands. $\mathbf{J}$ Clin Endocrinol Metab 2012; 97: E1499-505.
[31] Cinti S, Sbarbati A. Ultrastructure of human parathyroid cells in health and disease. Microsc Res Tech 1995; 32: 164-79.

[32] Tanaka Y, Funahashi H, Imai T, Seo H, Tominaga Y, Tahagi H. Oxyphil cell function in secondary parathyroid hyperplasia. Nephron 1996; 73: 580-6.

[33] Roth SI. The ultrastructure of primary water-clear cell hyperplasia of the parathyroid glands. Am J Pathol 1970; 61: 233-48.

[34] Emura S, Shoumura S, Utsumi M, et al. Ultrastructure of a water-clear cell in the golden hamster parathyroid gland. J Electron Microsc 1990; 39: $172-7$.

[35] Emura S, Shoumura S, Isono H. Ultrastructure of the water-clear cell in the rabbit parathyroid gland. Arch Histol Cytol 1992; 55: 159-66.

[36] Haynes JI. Parathyroid morphology of the brush-tail possum, Trichosurus vulpecula. Anat Rec 1995; 241: 401-10.

[37] Chen H, Emura S, Shoumura S. Ultrastructure of the water-clear cell in the parathyroid gland of SAMP6 mice. Tissue Cell 2006; 38: 187-92.

[38] Bischoff SC. Role of mast cells in allergic and non-allergic immune responses: comparison of human and murine data. Nat Rev Immunol 2007; 7: 93-104.

[39] Anderson TJ. Mast cells in parathyroid glands of hyperparathyroidism. J Clin Pathol 1974; 27: 31-4.

[40] Turner RT, Iwaniec UT, Marley K, Sibonga JD. The role of mast cells in parathyroid bone disease. J Bone Miner Res 2010; 25: 1637-49.

[41] Chen H, Hayakawa D, Emura S, et al. Morphological identification of the lipid-storing cells in golden hamster parathyroid glands after vitamin A treatment. Histol Histopathol 2001;16: 793-800.

[42] Chen H, Hayakawa D, Emura S, et al. Macrophages in the hamster parathyroid gland: immunohistochemical and ultrastructural investigations. Okajimas Folia Anat Jpn 1999; 76: 221-9.

[43] Magno AL, Ward BK, Ratajczak T. The calcium-sensing receptor: a molecular perspective. Endocr Rev 2011; 32: 3-30.

[44] Habener JF, Rosenblatt M, Potts JT Jr. Parathyroid hormone: biochemical aspects of biosynthesis, secretion, action, and metabolism. Physiol Rev 1984; 64: 985-1053.

[45] Kumar R, Thompson JR. The regulation of parathyroid hormone secretion and synthesis. J Am Soc Nephrol 2011; 22: 216-24.

[46] Shoback DM, Membreno LA, McGhee JG. High calcium and other divalent- cations increase inositol trisphosphate in bovine parathyroid cells. Endocrinology 1988; 123: 382-9.

[47] Nemeth EF, Carafoli E. The role of extracellular calcium in the regulation of intracellular calcium and cellfunction-introduction. Cell Calcium 1990; 11: 319-21.

[48] Brown EM, Gamba G, Riccardi D, et al. Cloning and characterization of an extracellular $\mathrm{Ca}^{2+}$-sensing receptor from bovine parathyroid. Nature 1993; 366: 575-80.

[49] Hu J, Spiegel AM. Structure and function of the human calciumsensing receptor: insights from natural and engineered mutations and allosteric modulators. J Cell Mol Med 2007; 11: 908-22.

[50] Brown EM, MacLeod RJ. Extracellular calcium sensing and extracellular calcium signaling. Physiol Rev 2001; 81: 239-97.

[51] Kifor O, Diaz R, Butters R, Kifor I, Brown EM. The calcium-sensing receptor is localized in caveolin-rich plasma membrane domains of bovine parathyroid cells. J Biol Chem 1998; 273: 21708-13.

[52] Carrillo-López N, Alvarez-Hernández D, González-Suárez I, et al. Simultaneous changes in the calcium- sensing receptor and the vitamin D receptor under the influence of calcium and calcitriol. Nephrol Dial Transplant 2008; 23: 3479-84.

[53] Ritter CS, Pande S, Krits I, Slatopolsky E, Brown AJ. Destabilization of parathyroid hormone mRNA by extracellular $\mathrm{Ca}_{2}^{+}$and the calcimimetic R-568 in parathyroid cells: role of cytosolic $\mathrm{Ca}$ and requirement for gene transcription. J Mol Endocrinol 2008; 40: 13-21.

[54] Farnebo F, Enberg U, Grimelius L, et al. Tumor-specific decreased expression of calcium sensing receptor messenger ribonucleic acid in sporadic primary hyperparathyroidism. J Clin Endocrinol Metab 1997; 82: 3481-6.

[55] Ho C, Conner DA, Pollak MR, et al. A mouse model of human familial hypocalciuric hypercalcemia and neonatal severe hyperparathyroidism. Nat Genet 1995; 11: 389-94. 